Published in final edited form as:

Prog Cardiovasc Dis. 2014 ; 56(4): 441-447. doi:10.1016/j.pcad.2013.09.012.

\title{
The Role of Exercise and Physical Activity in Weight Loss and Maintenance
}

\author{
Damon L. Swift, Ph.D. ${ }^{1,2}$, Neil M. Johannsen, Ph.D. ${ }^{3,5}$, Carl J. Lavie, M.D. ${ }^{3,6}$, Conrad P. \\ Earnest, Ph.D. ${ }^{4}$, and Timothy S. Church, M.D., M.P.H., Ph.D. ${ }^{3}$ \\ ${ }^{1}$ Department of Kinesiology, East Carolina University, Greenville, NC 27858. \\ ${ }^{2}$ Center for Health Disparities, East Carolina University, Greenville, NC 27858. \\ ${ }^{3}$ Departments of Preventive Medicine, Pennington Biomedical Research Center, Baton Rouge \\ LA, 70808 \\ ${ }^{4}$ Department for Health, University of Bath, Bath, UK \\ ${ }^{5}$ Department of Kinesiology, Louisiana State University, Baton Rouge LA, 70803 \\ ${ }^{6}$ Department of Cardiovascular Diseases, John Ochsner Heart and Vascular Institute, Ochsner \\ Clinical School-The University of Queensland School of Medicine, New Orleans, LA 70121.
}

\begin{abstract}
This review explores the role of physical activity (PA) and exercise training (ET) in the prevention of weight gain, initial weight loss, weight maintenance, and the obesity paradox. In particular, we will focus the discussion on the expected initial weight loss from different ET programs, and explore intensity/volume relationships. Based on the present literature, unless the overall volume of aerobic ET is very high, clinically significant weight loss is unlikely to occur. Also, ET also has an important role in weight regain after initial weight loss. Overall, aerobic ET programs consistent with public health recommendations may promote up to modest weight loss $(\sim 2 \mathrm{~kg})$, however the weight loss on an individual level is highly heterogeneous. Clinicians should educate their patients on reasonable expectations of weight loss based on their physical activity program and emphasize that numerous health benefits occur from PA programs in the absence of weight loss.
\end{abstract}

\section{Keywords}

Weight loss; exercise training; physical activity; weight regain

\section{Rationale for weight loss in overweight and obese patients}

In the United States, $66.3 \%$ of adults are overweight or obese ${ }^{1}$, which represents a major public health concern. The total medical cost associated with treating obesity exceeds $\$ 140$ billion annually, and represents approximately $9.1 \%$ of annual medical expenditures ${ }^{2}$.

\footnotetext{
(c) 2013 Elsevier Inc. All rights reserved.

Address for Correspondence: Damon L. Swift, Ph.D. East Carolina University 107 FITT Building Greenville, NC 27858 Phone: (252) 737-1338 Fax: (252) 737-1299 Swiftd@ecu.edu.

Publisher's Disclaimer: This is a PDF file of an unedited manuscript that has been accepted for publication. As a service to our customers we are providing this early version of the manuscript. The manuscript will undergo copyediting, typesetting, and review of the resulting proof before it is published in its final citable form. Please note that during the production process errors may be discovered which could affect the content, and all legal disclaimers that apply to the journal pertain.
} 
Obesity is a major risk factor for many cardiovascular (CV) diseases such as coronary heart disease (CHD), heat failure (HF), stroke, ventricular dysfunction, and cardiac arrhythmias ${ }^{3}$. The American Heart Association's scientific statement on obesity and weight loss ${ }^{3}$ recommends weight loss in overweight and obese patients to reduce the severity of CV risk factors. Weight loss in these patients have been associated with improvements in many cardiometabolic risk factors such as prevalence of the metabolic syndrome, insulin resistance, type 2 diabetes (T2DM), dyslipidemia, hypertension, pulmonary disease, CV disease, and inflammation ${ }^{3}$. Clinically significant weight loss ( $\geq 5 \%$ of baseline body weight) has been shown to be more effective in reducing CV and T2DM risk factors ${ }^{4}$. Thus, a strong rationale exists for clinicians to advocate that overweight and obese patients attempt at least modest weight loss. Recent epidemiological evidence has emerged showing greater survival in adults with CV diseases with higher obesity levels compared to lower levels, which has been coined "the obesity paradox" ${ }^{5}$. Although, the findings of the obesity paradox have been verified in several studies within different clinical populations ${ }^{6-8}$, at the present time, little evidence exists that lower survival is observed in adults with CV diseases after modest or clinically significant weight loss.

High physical activity (PA) levels or exercise training (ET) should be an integral part of any treatment plan for obese individuals regardless of weight loss goals, and is associated with numerous $\mathrm{CV}$ benefits ${ }^{9}$. High levels of PA and cardiorespiratory fitness (CRF) are inversely associated with CV disease, T2DM and all-cause mortality ${ }^{10}$. Several epidemiological studies even suggest that high levels of PA or CRF attenuates the health risk of obesity ${ }^{11-13}$. Moreover, CRF levels have been shown to alter the relationship of the obesity paradox ${ }^{14}$, where high CRF level is associated with greater survival in all body mass index (BMI) categories. So above all, clinicians should always encourage their patients to adhere to ET programs or engage in regular PA regardless of the weight loss achieved.

The present American College of Sports Medicine (ACSM) recommendations for physical activity to maintain health ${ }^{9}$ and promote weight loss ${ }^{15}$ are summarized in Figure 1. Strong evidence exists that PA can attenuate weight gain in those at risk for obesity, and many ET programs are capable of producing at least modest weight loss $(\sim 2 \mathrm{~kg}){ }^{15}$. A question often encountered in the clinical setting from patients is how much exercise is needed to lose weight and what type of ET should be performed. Overall, the changes in weight in response to ET without caloric restriction are highly heterogeneous and individual differences can span weight gain to clinically significant weight loss ${ }^{16}$. Clinicians should consult their patients on what are reasonable expectations based on their specific weight loss program. In the following paper, we will discuss the role of PA and ET in the prevention of weight gain, the expected weight loss from different ET types/modalities, how much PA is necessary to reduce recidivism following weight loss, and further discuss the obesity paradox.

\section{Physical activity and the prevention of weight gain}

Changes in weight are affected by the amount of energy expended versus the amount of energy consumed ${ }^{17}$. Therefore, if the energy expenditure remains low, but dietary consumption levels are in excess, weight gain will occur. Several researchers have argued that declines in PA both in occupational ${ }^{18}$ and leisure settings ${ }^{19}$ may have an important role in the increase in obesity rates over the last 30+ years. Furthermore, many epidemiological studies suggest that PA has an important role in weight gain 15,19-21. Williamson et al. ${ }^{22}$ using data from the National Health and Nutrition Examination Survey observed that low levels of self-reported recreational PA was associated with a 3-fold greater risk of major weight gain in men and almost a 4-fold in women. In a prospective study of 34,079 middle aged women (mean: 52.2 yrs), Lee et al. ${ }^{20}$ observed that in women the risk of weight gain over a three year period was $11 \%$ greater in women who participated 
in less than 7.5 metabolic equivalent (MET).hr/wk compared to women who participated in greater than $21 \mathrm{MET} \cdot \mathrm{hr} / \mathrm{wk}$ (approximately 300 minutes/week of moderate PA). Several studies using the Aerobic Center Longitudinal Study database have observed that CRF level ${ }^{23}$, PA level ${ }^{24}$, and change in PA level ${ }^{24}$ are inversely associated with future weight gain. Clearly, PA and CRF levels have an important role in weight gain for those at risk.

Researchers have speculated on the amount of PA necessary to prevent weight gain ${ }^{15,21}$. The ACSM position stand ${ }^{15}$ recommends 150-250 minutes per week of moderate to vigorous PA, with an energy equivalent of 1,200 to 2,000 kcals per week. Saris et al. ${ }^{21}$ recommended that PA levels of 225 to 300 minutes per week were necessary to prevent the transition of normal weight to overweight or overweight to obese. Thus, clinicians should always recommend that patients engage in regular ET even if they are normal weight, and certainly if they are at risk for becoming overweight or obese.

\section{Weight loss from specific exercise programs in overweight and obese patients}

In the following sections, we will discuss several different PA strategies for weight loss in obese patients and describe the overall likelihood for nominal and clinically significant weight loss. When possible, we have provided data from large randomized controlled trials to support our conclusions. Table 1 summarizes the expected weight change from different exercise training programs discussed in the following sections.

\section{Pedometers to increase physical activity and promote weight loss}

Pedometers are devices that count the number of steps that an individual accumulates throughout the day ${ }^{25}$. The current consensus states that obtaining less than 5,000 steps per day is indicative of sedentary behavior, whereas greater than 8,000 or 10,000 steps suggests a more active lifestyle. Clinicians can utilize pedometers to assess a patient's current PA habits, and as a tool for patients to increase their PA levels. Pedometer-based interventions where sedentary participants increase PA levels to 10,000 steps or 2000-4,000 step/day above baseline levels have shown some positive effects for weight loss; however, in general weight loss tends to very modest $(<2 \mathrm{~kg}){ }^{25,26}$. Richardson et al. ${ }^{27}$ performed a metaanalysis on pedometer-based interventions without caloric restriction (median duration: 16 weeks), and observed that pooled estimated change in weight was $-1.3 \mathrm{~kg}$. Bravata et al. ${ }^{26}$ performed a meta-analysis regarding the physiological effects of pedometer-based interventions on risk factors for $\mathrm{CV}$ disease, and has observed significant reductions in BMI $\left(-0.38 \mathrm{~kg} / \mathrm{m}^{2}\right)$, systolic blood pressure $(-3.8 \mathrm{mmHg})$, diastolic blood pressure $(-0.3 \mathrm{mmHg})$, but no significant reduction in cholesterol, triglyceride, or fasting glucose levels. Although, asking a participant to walk a certain amount of steps can promote favorable changes in CV disease risk factors and may provide minimal weight loss, little empirical evidence exists that a pedometer-based program alone without caloric restriction can promote clinically significant weight loss.

\section{Weight Loss from Aerobic Exercise at Public Health recommendation levels}

Clinical trials of ET that report no weight loss or modest weight loss ( $<5 \mathrm{kgs})$ still report numerous health benefits for overweight and obese adults with risk factors for disease. These benefits include improving CRF ${ }^{28,29}$, glucose control ${ }^{30,31}$, endothelial function ${ }^{32,33}$, lipoprotein particle size ${ }^{34}$, high density lipoprotiein ${ }^{35}$, and quality of life ${ }^{36,37}$. Weight loss as a result of aerobic ET is very heterogonous, and the overall response is related not only to total energy expenditure, but also compensatory changes in dietary caloric intake ${ }^{17}$. Large 
randomized controlled trials (RCTs) which have evaluated the change in weight following aerobic ET programs consistent with PA recommendations have observed either no changes in weight or only modest weight loss.

The following studies represent the strongest research design to evaluate changes in weight from aerobic ET as they have a large sample size of overweight or obese individuals at baseline, supervised ET sessions, strong adherence to their aerobic ET program, and comparison of weight change against a control group. The Dose Response to Exercise in Women (DREW) study 28 ( $\mathrm{n}=464)$ observed no significant changes in body weight in postmenopausal women exercising at $50 \%(-0.4 \mathrm{~kg}), 100 \%(-2.2 \mathrm{~kg})$ and $150 \%(-0.6 \mathrm{~kg})$ of public health guidelines for 6 months despite greater than $89 \%$ adherence in all ET groups. The Inflammation and Exercise (INFLAME) study $(\mathrm{n}=129)^{38}$ observed no significant change in body weight $(-0.4 \mathrm{~kg})$ compared to the control group $(0.1 \mathrm{~kg})$ after 4 months of ET in adults with elevated C-reactive protein levels at baseline. The Studies of a Targeted Risk Reduction Intervention through Defined Exercise (STRRIDE) study ${ }^{34}$ ( $\mathrm{n}=84$ ) observed significant, but minimal weight loss in those exercising at low amount/moderate intensity (-0.6 kg, $176 \mathrm{~min} /$ week), low amount/high intensity $(-0.2 \mathrm{~kg}, 117 \mathrm{~min} /$ week ), or high amount high intensity ( $-1.5 \mathrm{~kg}, 171$ minutes/week) following 6 months of aerobic ET. The Diabetes Aerobic and Resistance Exercise (DARE) study ${ }^{31}(\mathrm{n}=251)$ observed significant weight loss in the aerobic ET group $(-0.74 \mathrm{~kg})$ compared to the control group after 22 weeks of intervention in adults with T2DM.

Thus, overweight and obese adults who adhere to an exercise program consistent with public health recommendations without a dietary plan involving caloric restriction can expect to experience weight loss in a range of no weight loss to approximately $2 \mathrm{kgs}$. Clinicians should caution their patients that the chances of substantial weight loss are unlikely at these ET levels without caloric restriction ${ }^{15}$. Regardless of the amount of weight loss, clinicians should emphasize that numerous health benefits occur in the absence of weight loss, and that maintenance of an active lifestyle will reduce the risk of future weight gain ${ }^{15,19}$. An important limitation of the present data in this area is that long-term (> 1 year) and timecourse studies are not currently available.

\section{Weight loss from high volume aerobic exercise training without caloric restriction}

Current ACSM recommendations state that exercise programs need to exceed $225 \mathrm{~min} / \mathrm{per}$ week in order to possibly induce clinically significant weight loss ${ }^{15}$. Supervised ET studies which have demonstrated clinically significant weight loss with aerobic ET (without caloric restriction) have far exceeded the minimum levels of physical activity according to public health definitions ${ }^{15}$. Ross et al. ${ }^{39}$ observed an $8 \%$ weight loss in obese men after 12 weeks of aerobic ET with no alterations in dietary habits(daily exercise sessions of $700 \mathrm{kcals}$ ). In a different study, Ross et al. ${ }^{40}$ observed an $6.8 \%$ weight loss in premenopausal women (BMI>27) following 14 weeks of aerobic ET with an energy expenditure of 500 kcals per session. In the Midwest Exercise Trial, Donnelly et al. ( $\mathrm{n}=131)$ observed a 5.3\% weight loss in men after 16 weeks of aerobic ET at approximately 2,000 kcals per week. In contrast, the women in the exercise group did not have a significant change in weight $(0.7 \mathrm{~kg})$ following the intervention, but the exercise program prevented the weight gain observed in the control group ( $2.9 \mathrm{~kg}$.) Thus, clinically significant weight loss is possible with aerobic ET without caloric restriction, but it requires a high ET volume. For the general population, these ET volumes may not be practical or sustainable. 


\section{Weight compensation for aerobic exercise training}

Individuals who lose less weight than expected based on their training energy expenditure have been termed "weight compensators." Several studies have examined weight compensation after aerobic exercise training. King et al. ${ }^{41}$ observed increased energy intake and increased fat intake in weight compensators compared to those that did not compensate for weight loss. Using data from the DREW study, Church et al. ${ }^{16}$ examined weight compensation in postmenopausal women who were required to perform ET at 50\%, 100\% and $150 \%$ of public health recommendations, and restricted the analysis to those who were $85 \%$ compliant to exercise training. The authors observed that the most weight compensation (less weight loss achieved than predicted from ET alone) occurred in the women exercising at $150 \%$ of the recommended volume. In fact, the amount of actual weight loss achieved in women exercising at $50 \%(-1.4 \mathrm{~kg})$ and $150 \%(-1.5 \mathrm{~kg})$ of the PA recommendations were virtually identical to each other despite the greater level of energy weekly energy expenditure in the $150 \%$ group. ${ }^{16}$. Thomas et al. ${ }^{17}$ performed an analysis of weight change from 15 aerobic ET interventions, and concluded that the major factors limiting the expected weight loss from aerobic ET were dietary compensation and low aerobic ET dose. At the present time, evidence is limited to explain whether other factors of the energy balance equation, including compensatory changes in non-exercise PA (except for perhaps older adults), resting metabolic rate, movement efficiency, or changes in lean mass, are responsible for weight compensation with ET.

\section{Contributing effects of aerobic exercise intensity or resistance training on weight loss?}

Vigorous intensity aerobic ET has been shown to have enhanced health benefits for important risk factors ${ }^{42}$, including visceral fat ${ }^{43}$, measures of glucose/insulin metabolism ${ }^{44}$, and CRF ${ }^{45-47}$, compared to moderate intensity aerobic ET. In terms of weight change, when different intensities of ET are matched for caloric expenditure or ET dose, both vigorous and moderate intensity aerobic ET result in similar amounts of weight loss. O'Donovan et al. ${ }^{47}$ in an RCT of 64 obese men observed similar changes in weight following 6 months of moderate intensity $(-1.1 \mathrm{~kg})$ and high intensity $(-0.5 \mathrm{~kg})$ aerobic ET. In the STRRIDE study, Kraus et al. ${ }^{34}$ observed similar weight loss in overweight/obese adults participating in 8 months of moderate $(-0.6 \mathrm{~kg})$ and high intensity $(-0.2 \mathrm{~kg})$ aerobic ET at the same exercise dose (14 kilocalories per kg per week). Vigorous intensity aerobic ET can contribute to greater weight loss if matched for session time compared to moderate intensity aerobic ET because the total energy expenditure is greater. Thus, if vigorous aerobic ET can be sustained and is enjoyable for the patient, the exercise program may induce additional health benefits and potentially increase the energy expenditure seen with exercise training (if replacing the exercise time of moderate intensity training).

Resistance ET and isometric exercises are important and sometimes overlooked aspects of an ET program that have many health benefits including increasing/maintaining muscular strength with aging (prevention of sarcopenia) and preserving bone mineral density 9,48 . Although, resistance ET alone contributes to the reduction of body fat, the effect on overall weight loss is minimal ${ }^{15}$. In the Health Benefits of Aerobic and Resistance Training (HART-D) study, Church et al. ${ }^{30}$ observed no significant change $(-0.3 \mathrm{~kg})$ in weight in the resistance ET group $(n=73)$ compared to a control group after the 9 month intervention. In the DARE trial ${ }^{31}$, no significant difference was observed between the resistance ET group and the control group $(0.3 \mathrm{~kg})$. Bateman et al. $(\mathrm{n}=86)$ observed no significant change in weight $(0.07 \mathrm{~kg})$ following 8 months of intervention in the STRIDDE AT/RT study ${ }^{49}$. Overall, little evidence exists that resistance training alone promotes weight loss. 
Very few randomized controlled trials have explored whether the combination of both aerobic and resistance ET leads to a greater reduction in body weight compared to aerobic ET alone. The available evidence from large randomized RCTs suggests similar weight losses after participating in a program composed of aerobic ET or combined aerobic and resistance ET ${ }^{30,31}$. However, combined programs may have enhanced effects for other health indicators such as glucose control. Observations from both the HART-D ${ }^{30}$ and DARE trials ${ }^{31}$ suggest that an ET program composed of both resistance and aerobic ET promotes greater changes in hemoglobin $\mathrm{A}_{1 \mathrm{C}}$ compared to aerobic $\mathrm{ET}$ alone in adults with T2DM.

\section{Is the weight loss achieved through caloric restriction enhanced by exercise training?}

The literature is clear that caloric restriction is more likely to result in clinically significant weight loss compared to aerobic ET alone; however, the present literature is less clear if weight loss from caloric restriction is enhanced by adding ET/PA. Wing et al. ${ }^{50}$ reported that, although ET and caloric restriction together may promote greater weight loss compared to caloric restriction alone, the differences in weight loss are not statistically significant. Miller et al. ${ }^{51}$ performed a meta-analysis of weight loss interventions and determined that rate of weight loss was similar after ET and caloric restriction $(1.0 \mathrm{~kg} / \mathrm{week})$ and caloric restriction alone $(0.98 \mathrm{~kg} / \mathrm{week})$. The rate of weight loss observed in both these interventions far exceeded that which can be achieved by ET only ( $0.2 \mathrm{~kg} / \mathrm{week})$. Thus, the present literature supports that the majority of the weight loss from combined ET and caloric restriction can be attributed to caloric restriction. However, as will be discussed in this review, PA has an important role in weight maintenance, as well as increasing CRF ${ }^{52}$, which improves in direct response to aerobic ET ${ }^{10}$, but not with caloric restriction alone.

\section{Diet versus Exercise Induced Weight Loss}

Another question that is often encountered in the clinical setting is if there is a difference between weight loss achieved through dietary means or through ET in terms of CV and T2DM risk factors. In an elegantly designed study, Ross et al. ${ }^{39}$ randomized obese men ( $\mathrm{n}=$ 52) to diet-induced weight loss, exercise induced weight loss, exercise without weight loss, or a control group for 3 months. The diet-induced and exercise-induced weight loss groups lost approximately $7 \mathrm{~kg}$ of weight (8\% weight reduction), and had significant reductions in total fat mass, visceral fat and increased glucose disposal. However, the ET-induced weight loss group had a greater reduction in total fat mass compared to the diet induced weight loss group. Importantly, the exercise-induced weight loss improved CRF whereas the dietary group did not. In the group who performed ET without weight loss, the participants still experienced reductions in visceral fat and increased CRFs.

The observations by Ross et al. reaffirm that an ET program still confers health benefits to obese patients even in the absence of weight loss. Although dieting without ET has potential CV benefits, ET should be encouraged by clinicians to help their patients improve CRF levels, which is an independent risk factor for CV diseases, T2DM and mortality ${ }^{10}$, and may further augment the negative energy balance created by caloric restriction. Lastly, Ross' observations suggest that there is a rationale for ET to be a part of weight loss programs as the authors observed greater changes in visceral fat, oral glucose tolerance, and glucose disposal in the ET group with clinically significant weight loss compared to the group with ET without weight loss group. 


\section{Exercise and Weight Maintenance}

The ACSM position stand on PA intervention strategies to promote weight loss and weight regain ${ }^{15}$ emphasize the distinction between the minimum levels of PA to maintain health (150 minutes per week) and higher levels of PA to prevent weight regain (200 minutes per week). Therefore, obese individuals who have successfully lost weight require a substantial amount of PA to maintain this weight loss. As indicated in the ACSM position stand ${ }^{15}$, several major limitations to research of PA on weight regain exist including the observational and the retrospective nature of the existing literature from randomized trials. However, several studies in this area deserve mentioning. Using data from a PA weight loss study, Jakicic et al. ${ }^{53}$ observed a dose response between the amount of self-reported PA per week and long-term success with weight loss at 18 months of intervention (composed of caloric restriction and ET). Adults who exercised greater than 200 minutes per week $(-13.1$ $\mathrm{kg}$ ) lost more weight compared to those who exercised between 150-199 min per week (-8.5 $\mathrm{kg}$ ), and those that exercised less than 150 minutes week $(-3.5 \mathrm{~kg})$. A different study by Jakicic et al. ${ }^{54}$ observed similar findings in post hoc analyses of a weight loss intervention composed of both caloric restriction and exercise training in women. After 12 months of intervention, women with greater than $200 \mathrm{~min} /$ week (13.6\%) had maintained significantly greater percentage of weight loss compared to those who had exercised at 150-199 min/ week (9.5\%), and less than $150 \mathrm{~min} /$ week (4.7\%). Lastly, Andersen et al. ${ }^{55}$ evaluated the effect of low-fat diet (1200 kcals/day) in combination with either structured aerobic ET or lifestyle activity (patients were advised to increase their PA to recommended levels), and both groups lost approximately $8 \mathrm{~kg}$ of weight following 16 weeks of intervention. Weight maintenance was monitored for 1 year after the intervention, and those who were the most active lost additional weight $(1.9 \mathrm{~kg})$ whereas the group that was the least active regained a substantial amount of weight $(4.9 \mathrm{~kg})$. These data suggest that PA has an important role in the amount of weight regain following successful weight loss. Clinicians should therefore advocate that their patients attempting to reduce recidivism after weight loss engage in PA levels above 200 minutes/week ${ }^{15}$.

\section{The rationale for exercise within weight management programs}

From the present literature, caloric restriction appears to have a more profound and consistent effect on weight loss compared to exercise training alone ${ }^{51}$. Therefore, clinicians may be tempted to advocate the use of caloric restriction in weight management plans. Importantly, PA contributes to the negative energy balance seen with caloric restriction. From a clinical perspective, both CRF and PA levels are established independent risk factors for CVD, T2DM and all-cause mortality ${ }^{10}$. Caloric restriction without exercise does not improve CRF levels ${ }^{39,52}$. As mentioned previously, ET has been shown to provide numerous health benefits even in the absence of weight loss. Therefore, if a patient is utilizing caloric restriction to lose weight, clinicians should always encourage an active lifestyle.

\section{The Obesity Paradox}

The only group where the clinical impact of weight loss may not be as clear is for individuals with established CV diseases. Recent evidence suggests that in individuals with $\mathrm{CV}$ disease, higher BMI levels are associated with better survival rates compared to those with lower levels ${ }^{5}$. This phenomenon which has been termed " the obesity paradox" has been shown in a variety of $\mathrm{CV}$ conditions such as heart failure, hypertension, and coronary heart disease ${ }^{5}$. Much of these data are epidemiological in nature, therefore reverse causation may be an important factor to consider. More research is needed to determine the extent to which the relationships explained by the obesity paradox in individuals investigating weight 
loss programs or actively losing weight to verify whether maintaining higher weight levels are protective against mortality in these populations. Further, many studies which show weight loss with PA as a component have shown improvements in CV disease risk factors ${ }^{9}$, progression to T2DM ${ }^{56}$, and mortality ${ }^{10}$. Importantly, higher CRF levels appear to be protective against mortality in all BMI categories ${ }^{14}$, and alter the relationship of the obesity paradox. Thus, the current literature suggests that overweight/obese adults with CVD should still participate in ET and a moderate weight loss program. However, further investigation of the obesity paradox is certainly warranted.

\section{Conclusions}

Exercise training, regardless of weight loss, provides numerous health benefits especially for overweight and obese individuals at risk for $\mathrm{CV}$ diseases or with current $\mathrm{CV}$ conditions. Although the weight loss from ET programs without caloric restriction are very heterogeneous, based on the present literature patients who engage in a PA program may experience modest weight $\operatorname{loss}(<2 \mathrm{~kg})$, but no weight loss is possible. Clinicians need to emphasize that substantial weight loss is unlikely to occur from a PA program unless the overall volume of ET is well above the minimum recommended levels. Patients wishing to lose weight should participate in physical activity and caloric restriction to improve the chances of weight loss. However, PA has a major role in the amount of weight regained after the initial weight loss. Overall clinicians should attempt to encourage participants to adhere to ET programs over the long-term regardless of the amount of weight loss achieved, as CV benefits are readily achieved in the absence of weight loss.

\section{Acknowledgments}

Supported in part by an NIDDK T-32 fellowship (Obesity from Genes to Man, T32 DK064584-06)

\section{Abbreviations}

$\begin{array}{ll}\text { ACSM } & \text { American College of Sports Medicine } \\ \text { CRF } & \text { Cardiorespiratory fitness } \\ \text { CHD } & \text { Coronary heart disease } \\ \text { CV } & \text { Cardiovascular } \\ \text { DREW } & \text { Dose Response to Exercise in Women } \\ \text { ET } & \text { Exercise training } \\ \text { HART-D } & \text { Health Benefits of Aerobic and Resistance Training } \\ \text { HF } & \text { Heart failure } \\ \text { INFLAME } & \text { Inflammation and Exercise } \\ \text { MET } & \text { Metabolic equivalent } \\ \text { PA } & \text { Physical activity } \\ \text { STRRIDE } & \text { Studies of a Targeted Risk Reduction Intervention through Defined Exercise } \\ \text { T2DM } & \text { Type 2 diabetes mellitus }\end{array}$

\section{References}

1. Ogden CL, Carroll MD, Curtin LR, et al. Prevalence of overweight and obesity in the united states, 1999-2004. JAMA. 2006; 295:1549-55. [PubMed: 16595758] 
2. Finkelstein EA, Trogdon JG, Cohen JW, et al. Annual medical spending attributable to obesity: Payer-and service-specific estimates. Health Aff (Millwood). 2009; 28:w822-w31. [PubMed: 19635784]

3. Klein S, Burke LE, Bray GA, et al. Clinical implications of obesity with specific focus on cardiovascular disease: A statement for professionals from the american heart association council on nutrition, physical activity, and metabolism: Endorsed by the american college of cardiology foundation. Circulation. 2004; 110:2952-67. [PubMed: 15509809]

4. Wing RR, Lang W, Wadden TA, et al. Benefits of modest weight loss in improving cardiovascular risk factors in overweight and obese individuals with type 2 diabetes. Diabetes Care. 2011; 34:1481-6. [PubMed: 21593294]

5. Lavie CJ, Milani RV, Ventura HO. Obesity and cardiovascular diseaserisk factor, paradox, and impact of weight loss. J Am Coll Cardiol. 2009; 53:1925-32. [PubMed: 19460605]

6. Galal W, Van Gestel YR, Hoeks SE, et al. The obesity paradox in patients with peripheral arterial disease. Chest. 2008; 134:925-30. [PubMed: 18641109]

7. Uretsky S, Messerli FH, Bangalore S, et al. Obesity paradox in patients with hypertension and coronary artery disease. The American Journal of Medicine. 2007; 120:863-70. [PubMed: 17904457]

8. Oreopoulos A, Padwal R, Kalantar-Zadeh K, et al. Body mass index and mortality in heart failure: A meta-analysis. Am Heart J. 2008; 156:13-22. [PubMed: 18585492]

9. Haskell WL, Lee I-M, Pate RR, et al. Physical activity and public health: Updated recommendation for adults from the american college of sports medicine and the american heart association. Med Sci Sports Exerc. 2007; 39:1423-34. [PubMed: 17762377]

10. Swift DL, Lavie CJ, Johannsen NM, et al. Physical activity, cardiorespiratory fitness, and exercise training in primary and secondary coronary prevention. Circ J. 2013; 77:281-92. [PubMed: 23328449]

11. Blair SN, Brodney S. Effects of physical inactivity and obesity on morbidity and mortality: Current evidence and research issues. Med Sci Sports Exerc. 1999; 31:S646. [PubMed: 10593541]

12. Wei M, Kampert JB, Barlow CE. Relationship between low cardiorespiratory fitness and mortality in normal-weight, overweight, and obese men. JAMA. 1999; 282:1547-53. [PubMed: 10546694]

13. Lee CD, Blair SN, Jackson AS. Cardiorespiratory fitness, body composition, and all-cause and cardiovascular disease mortality in men. The American Journal of Clinical Nutrition. 1999; 69:373-80. [PubMed: 10075319]

14. McAuley PA, Kokkinos PF, Oliveira RB, et al. Obesity paradox and cardiorespiratory fitness in 12,417 male veterans aged 40 to 70 years. Mayo Clin Proc. 2010; 85:115-21. [PubMed: 20118386]

15. Donnelly JE, Blair SN, Jakicic JM, et al. Appropriate physical activity intervention strategies for weight loss and prevention of weight regain for adults. Med Sci Sports Exerc. 2009; 41:459-71. [PubMed: 19127177]

16. Church TS, Martin CK, Thompson AM, et al. Changes in weight, waist circumference and compensatory responses with different doses of exercise among sedentary, overweight postmenopausal women. PLoS ONE. 2009:4.

17. Thomas DM, Bouchard C, Church T, et al. Why do individuals not lose more weight from an exercise intervention at a defined dose? An energy balance analysis. Obes Rev. 2012; 13:835-47. [PubMed: 22681398]

18. Church TS, Thomas DM, Tudor-Locke C, et al. Trends over 5 decades in u.S. Occupation-related physical activity and their associations with obesity. PLoS ONE. 2011; 6:e19657. [PubMed: 21647427]

19. Fogelholm M, Kukkonen-Harjula K. Does physical activity prevent weight gain--a systematic review. Obes Rev. 2000; 1:95-111. [PubMed: 12119991]

20. Lee I, Djoussé L, Sesso HD, et al. Physical activity and weight gain prevention. JAMA. 2010; 303:1173-9. [PubMed: 20332403]

21. Saris WHM, Blair SN, Van Baak MA, et al. How much physical activity is enough to prevent unhealthy weight gain? Outcome of the iaso 1st stock conference and consensus statement. Obes Rev. 2003; 4:101-14. [PubMed: 12760445] 
22. Williamson DF, Madans J, Anda RF, et al. Recreational physical activity and ten-year weight change in a us national cohort. Int J Obes Relat Metab Disord. 1993; 17:279-86. [PubMed: 8389337]

23. Van Wye G, Dubin JA, Blair SN, et al. Adult obesity does not predict 6-year weight gain in men: The aerobics center longitudinal study. Obesity. 2007; 15:1571-7. [PubMed: 17557995]

24. Di Pietro L, Dziura J, Blair SN. Estimated change in physical activity level (pal) and prediction of 5-year weight change in men: The aerobics center longitudinal study. Int J Obes Relat Metab Disord. 2004; 28:1541-7. [PubMed: 15543159]

25. Tudor-Locke C, Bassett D Jr. How many steps/day are enough? Sports Med. 2004; 34:1-8. [PubMed: 14715035]

26. Bravata DM, Smith-Spangler C, Sundaram V, et al. Using pedometers to increase physical activity and improve health. JAMA: The Journal of the American Medical Association. 2007; 298:2296304. [PubMed: 18029834]

27. Richardson CR, Newton TL, Abraham JJ, et al. A meta-analysis of pedometer-based walking interventions and weight loss. The Annals of Family Medicine. 2008; 6:69-77.

28. Church TS, Earnest CP, Skinner JS, et al. Effects of different doses of physical activity on cardiorespiratory fitness among sedentary, overweight or obese postmenopausal women with elevated blood pressure. JAMA. 2007; 297:2081-91. [PubMed: 17507344]

29. Johannsen NM, Swift DL, Lavie CJ, et al. Categorical analysis of the impact of aerobic and resistance exercise training, alone and in combination, on cardiorespiratory fitness levels in patients with type 2 diabetes mellitus: Results from the hart-d study. Diabetes Care. 2013

30. Church TS, Blair SN, Cocreham S, et al. Effects of aerobic and resistance training on hemoglobin a1c levels in patients with type 2 diabetes. JAMA: The Journal of the American Medical Association. 2010; 304:2253-62. [PubMed: 21098771]

31. Sigal RJ, Kenny GP, Boulé NG, et al. Effects of aerobic training, resistance training, or both on glycemic control in type 2 diabetes. Ann Intern Med. 2007; 147:357-69. [PubMed: 17876019]

32. Swift DL, Earnest CP, Blair SN, et al. The effect of different doses of aerobic exercise training on endothelial function in postmenopausal women with elevated blood pressure: Results from the drew study. Br J Sports Med. 2012; 46:753-8. [PubMed: 21947813]

33. Sixt S, Rastan A, Desch S, et al. Exercise training but not rosiglitazone improves endothelial function in prediabetic patients with coronary disease. Eur J Cardiovasc Prev Rehabil. 2008; 15:473-8. [PubMed: 18677174]

34. Kraus WE, Houmard JA, Duscha BD, et al. Effects of the amount and intensity of exercise on plasma lipoproteins. N Engl J Med. 2002; 347:1483-92. [PubMed: 12421890]

35. Kodama STSSK, et al. Effect of aerobic exercise training on serum levels of high-density lipoprotein cholesterol: A meta-analysis. Arch Intern Med. 2007; 167:999-1008. [PubMed: 17533202]

36. Myers VH, McVay MA, Brashear MM, et al. Exercise training and quality of life in individuals with type 2 diabetes: A randomized controlled trial. Diabetes Care. 2013

37. Martin CK, Church TS, Thompson AM, et al. Exercise dose and quality of life: A randomized controlled trial. Arch Intern Med. 2009; 169:269-78. [PubMed: 19204218]

38. Church TS, Earnest CP, Thompson AM, et al. Exercise without weight loss does not reduce creactive protein: The inflame study. Med Sci Sports Exerc. 2010; 42:708-16. [PubMed: 19952828]

39. Ross R, Dagnone D, Jones PJH, et al. Reduction in obesity and related comorbid conditions after diet-induced weight loss or exercise-induced weight loss in men. Ann Intern Med. 2000; 133:92103. [PubMed: 10896648]

40. Ross R, Janssen I, Dawson J, et al. Exercise-induced reduction in obesity and insulin resistance in women: A randomized controlled trial. Obes Res. 2004; 12:789-98. [PubMed: 15166299]

41. King NA, Hopkins M, Caudwell P, et al. Individual variability following 12 weeks of supervised exercise: Identification and characterization of compensation for exercise-induced weight loss. Int J Obes. 2008; 32:177-84.

42. Swain DP, Franklin BA. Comparison of cardioprotective benefits of vigorous versus moderate intensity aerobic exercise. Am J Cardiol. 2006; 97:141-7. [PubMed: 16377300] 
43. Irving BA, Davis CK, Brock DW, et al. Effect of exercise training intensity on abdominal visceral fat and body composition. Med Sci Sports Exerc. 2008; 40:1863-72. [PubMed: 18845966]

44. DiPietro L, Dziura J, Yeckel CW, et al. Exercise and improved insulin sensitivity in older women: Evidence of the enduring benefits of higher intensity training. J Appl Physiol. 2006; 100:142-9. [PubMed: 16141382]

45. Savage MP, Petratis MM, Thomson WH, et al. Exercise training effects on serum lipids of prepubescent boys and adult men. Med Sci Sports Exerc. 1986; 18:197-204. [PubMed: 3702647]

46. Boulé NG, Kenny GP, Haddad E, et al. Meta-analysis of the effect of structured exercise training on cardiorespiratory fitness in type 2 diabetes mellitus. Diabetologia. 2003; 46:1071-81. [PubMed: 12856082]

47. O'Donovan G, Owen A, Bird SR, et al. Changes in cardiorespiratory fitness and coronary heart disease risk factors following $24 \mathrm{wk}$ of moderate- or high-intensity exercise of equal energy cost. J Appl Physiol. 2005; 98:1619-25. [PubMed: 15640382]

48. Winett RA, Carpinelli RN. Potential health-related benefits of resistance training. Prev Med. 2001; 33:503-13. [PubMed: 11676593]

49. Bateman LA, Slentz CA, Willis LH, et al. Comparison of aerobic versus resistance exercise training effects on metabolic syndrome (from the studies of a targeted risk reduction intervention through defined exercise - strride-at/rt). Am J Cardiol. 2011; 108:838-44. [PubMed: 21741606]

50. Wing RR. Physical activity in the treatment of the adulthood overweight and obesity: Current evidence and research issues. Med Sci Sports Exerc. 1999; 31:S547. [PubMed: 10593526]

51. Miller WC, Koceja DM, Hamilton EJ. A meta-analysis of the past 25 years of weight loss research using diet, exercise or diet plus exercise intervention. Int J Obes Relat Metab Disord. 1997; 21:941. [PubMed: 9347414]

52. Redman LM, Heilbronn LK, Martin CK, et al. Effect of calorie restriction with or without exercise on body composition and fat distribution. J Clin Endocrinol Metab. 2007; 92:865-72. [PubMed: 17200169]

53. Jakicic JM, Winters C, Lang W, et al. Effects of intermittent exercise and use of home exercise equipment on adherence, weight loss, and fitness in overweight women: A randomized trial. JAMA. 1999; 282:1554-60. [PubMed: 10546695]

54. Jakicic JM, Marcus BH, Gallagher KI, et al. Effect of exercise duration and intensity on weight loss in overweight, sedentary women: A randomized trial. JAMA. 2003; 290:1323-30. [PubMed: 12966123]

55. Andersen RE, Wadden TA, Bartlett SJ, et al. Effects of lifestyle activity vs structured aerobic exercise in obese women: A randomized trial. JAMA. 1999; 281:335-40. [PubMed: 9929086]

56. Diabetes Prevention Program Reaserch Group. Reduction in the incidence of type 2 diabetes with lifestyle intervention or metformin. N Engl J Med. 2002; 346:393-403. [PubMed: 11832527] 


\section{Recommendations for Physical Activity:}

- Maintaining and improving health: $150 \mathrm{~min} . /$ week

- Prevention of weight gain: 150-250 min./week

- Promote clinically significant weight loss: $225-420 \mathrm{~min} /$ week

- Prevention of weight gain after weight loss: 200-300 min./week

Figure 1.

Current recommendations for amounts of physical activity based on goals for maintaining health, prevention of weight gain, promoting clinically significant weight loss, and prevention of weight gain after successful weight loss. Recommendations are based on the American College of Sports Medicine position stand of Appropriate Physical Activity Intervention Strategies for Weight Loss and Prevention of Weight Regain for Adults. 


\section{Table 1}

Expected initial weight loss and possibly of producing clinically significant weight loss from different modalities of exercise training

\begin{tabular}{|l|c|c|}
\hline Modality & Weight Loss & Clinically significant weight loss \\
\hline Pedometer-based step goal & Range: 0 to $1 \mathrm{~kg}$ of weight loss & Unlikely \\
\hline Aerobic Exercise Training only & Range: 0 to $2 \mathrm{~kg}$ of weight loss & $\begin{array}{c}\text { Possible, but only with extremely high exercise } \\
\text { volumes }\end{array}$ \\
\hline Resistance Training only & None & Unlikely \\
\hline Aerobic and Resistance training only & Range: 0 to $2 \mathrm{~kg}$ of weight loss & $\begin{array}{c}\text { Possible, but only with extremely high volumes } \\
\text { of aerobic exercise training }\end{array}$ \\
\hline $\begin{array}{l}\text { Caloric restriction combined with aerobic exercise } \\
\text { training }\end{array}$ & Range: $-9 \mathrm{~kg}$ to $-13 \mathrm{~kg}$ & Possible \\
\hline
\end{tabular}

